\title{
ANCESTRALIDADE, COMUNIDADE E DIALOGICIDADE
}

\author{
ANCESTRALITY, COMUNITY AND DIALOGICALITY
}

\section{Emanoel Luís Roque Soares ${ }^{1}$ Maria Aparecida Lima Silva ${ }^{2}$}

Resumo: A luta por uma educação de qualidade sempre ocorreu no cenário político brasileiro, por meio dos movimentos sociais populares, principalmente, porque a maioria das pessoas afrodescendentes não tinha o privilégio da educação. Como fruto da luta, principalmente do movimento negro, os afrodescendentes foram privilegiados na educação, através da Lei 10.639 de 09 de janeiro de 2003. A desigualdade racial que caminha ao lado da desigualdade de renda foi construída ao longo do processo histórico, político e social do Brasil que, diferentemente, afeta a população branca e negra, mas, de modo particular, os negros nas condições de vida, emprego e escolaridade. Início do Século XXI, período em que a educação afrodescendente começou a ficar em evidência, afinal explodiam os debates, os encontros e os congressos sobre a temática, o Programa Conexões de Saberes, da UFRB, em suas Rodas de Saberes e Formação trazia à tona os saberes populares da região do Recôncavo da Bahia, representados pelos estudantes, suas famílias e grupos de origem, aprendendo com os mais velhos ou aqueles que detêm a memória da região, como as lalorixás dos terreiros de Candomblé, como os Mestres da Capoeira, como as pioneiras do Samba-de-Roda e na Agricultura de subsistência. O objetivo deste texto é analisar a permanecia de estudantes de origem popular na UFRB com enfoque nas histórias de vida e formação, o instrumento aplicado (entrevistas) possibilitou o diálogo entre os atores da pesquisa e, através das opiniões e atitudes, foi estabelecida uma interface entre os fatos vivenciados e a formação acadêmica.

Palavras-chave educação; Universidade Federal do Recôncavo da Bahia; afrodescendente.

Abstract: The struggle for quality education through the social popular movements is well known in the Brazilian political scenario, especially because the majority of African descendants did not have the privilege of education. The black movement political fight resulted in Law 10.639 of January 9th 2003 which gave the African descendants access to education. Racial inequality goes hand in hand with income inequality resulting from historical, political and social processes that affect black and white Brazilian communities in different ways, particularly the former with regard to standard of living, work conditions and education. At the beginning of the XXI century, African descendants' education was finally discussed in debates, meetings and conferences. The tutorial program Knowledge in Connection (Conexão de Saberes) in its Knowledge and Qualification Rounds brought up the Recôncavo's region popular knowledge represented by students, their families and origin groups, focusing on the learning with the elder or with those who hold the regional memories, such as lalorixás (religious candomblê leaders), Capoeira masters, Samba-de-Roda pioneers and subsistence farming members. The purpose of this paper is to analyze the remained of popular origin students in UFRB focusing on life stories and training, applied instrument (interviews) enabled the dialogue among research actors and, through the opinions and attitudes, an interface was established among experienced facts and academic training.

Keywords: education; Universidade Federal do Recôncavo da Bahia; African descendants.

\footnotetext{
${ }^{1}$ Doutor em Educação pela Universidade Federal do Ceará - UFC, Brasil. Professor de Filosofia da Educação e Filosofia da Ancestralidade da Universidade Federal do Recôncavo da Bahia - UFRB, Brasil. E-mail: emares@ufrb.edu.br.

${ }^{2}$ Mestre em Estudos Interdisciplinares Sobre a Universidade-IHAC/UFBA, Brasil. Técnico-Administrativo da Universidade Federal do Recôncavo da Bahia - UFRB /Centro de Formação de Professores, Brasil. E-mail: mals@ufrb.edu.br.
} 


\section{INTRODUÇÃO}

Até o início do século XXI, havia uma discrepância muito grande entre as regiões sudeste e nordeste quanto ao número de universidades existentes. A Região Nordeste, principalmente no interior, por muito tempo, não abrigava os estudantes de nível superior nas suas próprias cidades, por conta de não existirem universidades federais para o contingente de jovens egressos das escolas do ensino médio.

O acesso à educação, principalmente à educação superior, sempre foi restrito a um grupo de pessoas que fazem parte da elite brasileira. Com um caráter elitista, a educação superior permaneceu, por várias décadas, limitando o acesso dos jovens negros de camadas populares a ingressarem na academia, o que, no início deste século, tornou necessária a consolidação de políticas para a democratização do acesso ao ensino superior.

Com a democratização do ensino, por meio do Programa de Apoio a Planos de Reestruturação e Expansão das Universidades Federais - REUNI, instituído pelo Decreto $n^{\circ}$ 6.096, de 24 de abril de 2007, ocorreu a expansão da educação de qualidade acadêmica e inclusiva, abrangendo cidades do interior, a exemplo da UFRB.

Nesta pesquisa, procuramos desvelar todas as dificuldades, alegrias e tristezas apresentadas pelos estudantes de origem popular durante a formação acadêmica na UFRB. Demonstramos que, ainda, há muito o que fazer em relação às políticas públicas e institucionais destinadas a esses jovens, e que ainda existem muitas lacunas para assegurar a permanência, com êxito, para todos. Preocupação para todos os profissionais da UFRB que devem estar comprometidos com os objetivos da universidade.

A permanência na universidade era a principal preocupação dos(as) jovens que ingressaram na UFRB. A maioria desses(as) jovens não tiveram informações no ensino médio sobre o ensino superior e não conheciam uma universidade.

Os (as) jovens entrevistados ressaltam o prazer e o orgulho de terem participado do Conexões de Saberes. Primeiro, porque foi construído pelas mãos e ideias dos estudantes, dos professores e dos coordenadores, o que revela o respeito às diferenças, à mutualidade e à solidariedade entre todos.

Os relatos confirmam que a participação no Conexões de Saberes contribuiu com a permanência na UFRB, o reconhecimento de sua etnia e da identidade como jovens de comunidades populares. Proporcionou aos jovens a elevação da autoestima e possibilidades de um futuro mais promissor para si e a família.

Sobre a metodologia das Rodas de saberes e Formação, os estudantes revelam o quanto se apropriaram dessa metodologia, não só nos encontros de formação dos conexistas com os alunos do $3^{\circ}$. Ano do ensino médio, das escolas públicas, como 
também nos momentos didático-pedagógicos, em sala de aula, na universidade, e na sua vida profissional. Eram momentos em que todos dialogavam e aprendiam, sem hierarquias e receios de serem inferiorizados por pertencerem a comunidades de origem popular.

\section{CONEXÕES DE SABERES NA UFRB}

A Universidade do Recôncavo da Bahia, criada em 2005, está situada numa região em que a população negra, desde meados do Século XIX, já representava a maioria, isso contribuiu para que a cultura do continente africano exercesse grande influência nas cidades do Recôncavo da Bahia.

Pioneira na criação de uma Pró-reitoria de políticas Afirmativas e Assuntos Estudantis - PROPAAE, a Universidade Federal do Recôncavo da Bahia - UFRB executa, a partir de 2006, as políticas afirmativas que garantem aos estudantes universitários oriundos de escolas públicas que se declaram pretos ou pardos, índios e remanescentes de quilombos, o acesso e a permanência.

Fazendo parte da política institucional da UFRB, o Projeto Conexões de Saberes, mantido pelo Governo Federal por intermédio da Secretaria de Educação Continuada Alfabetização e Diversidade - SECAD, em parceria com o Observatório de Favelas, teve duas versões, entre 2008 e 2011.

O Projeto Conexões de Saberes da UFRB utilizou a pedagogia do diálogo entre os jovens universitários e os das comunidades populares que viviam no entorno da universidade, nos municípios do Recôncavo da Bahia, ver mapa na Figura 1 (Amargosa, Santo Antônio de Jesus, Cruz das Almas e Cachoeira), com o objetivo de aproximar os saberes e fomentar o respeito, considerando as experiências individuais vividas, não só nas comunidades como também no âmbito educacional. Os momentos de encontros educacionais e culturais do Programa aconteciam na universidade e, também, fora dela, nas escolas, com alunos do $3^{\circ}$. Ano do ensino médio. Cada grupo de universitários que atuava no município aprendia, ao tempo em que também ensinava. 
Figura 1 - Recôncavo da Bahia

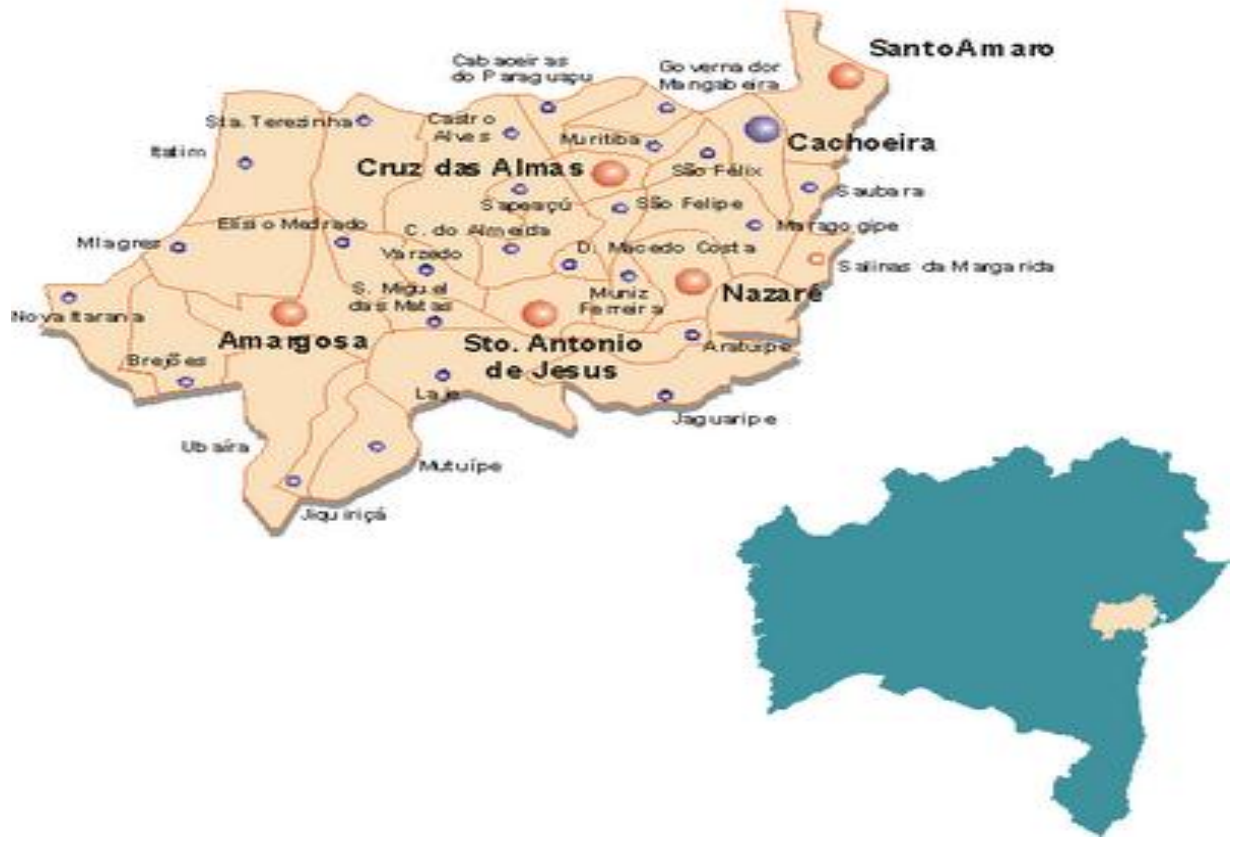

Fonte: Midiareconcavo, 2013.

A primeira versão do Programa Conexões de Saberes: diálogos entre a universidade e as comunidades populares (2008 - 2010) promoveu debates sobre temas pertinentes ao currículo das escolas e a formação dos estudantes universitários, com o intuito de contribuir com a implantação do ensino de História e Cultura AfroBrasileira e Africana na Educação Básica - Lei 10.639/03. Na segunda versão, Conexões de Saberes: diálogos entre a UFRB e os territórios de identidade do Recôncavo e do Vale do Jiquiriçá, (2010 - 2011), os estudantes universitários desenvolveram atividades de pesquisa, visitando as feiras livres de suas cidades, localizadas no interior do Recôncavo da Bahia, com intuito de adquirir conhecimento de iniciação cientifica, produção de textos e letramento, Em consonância com os referenciais nacionais do Programa, o Projeto da UFRB também consolidou a concepção e a intencionalidade político-pedagógica da extensão universitária, valorizando as trajetórias escolares e existenciais dos estudantes universitários e os saberes acumulados em suas trajetórias de vida. 
Tabela 1 - Caracterização / Identidade dos Integrantes da primeira versão do Conexões de Saberes

\begin{tabular}{|c|c|c|c|c|c|}
\hline Estudante & $\underline{\text { Sexo }}$ & $\begin{array}{c}\text { Data de } \\
\text { Nascimento }\end{array}$ & $\frac{\text { Cidade de }}{\text { Origem }}$ & Curso & Campus \\
\hline Rosário & $\mathrm{F}$ & 26.06 .1980 & Valença & História & Cachoeira \\
\hline S. da Silva & $M$ & 16.01 .1987 & Santo Amaro & Comunicação & Cachoeira \\
\hline Anunciação & $M$ & 15.03 .1983 & Salvador & Agronomia & Cruz das Almas \\
\hline $\begin{array}{l}\text { S. de } \\
\text { Oliveira }\end{array}$ & $\mathrm{F}$ & 06.04 .1985 & $\begin{array}{l}\text { Riachão de } \\
\text { Jacuípe }\end{array}$ & Agronomia & Cruz das Almas \\
\hline $\begin{array}{l}\text { Silva } \\
\text { Santos }\end{array}$ & $\mathrm{F}$ & 02.09.1982 & $\begin{array}{l}\text { Governador } \\
\text { Mangabeira }\end{array}$ & Comunicação & Cachoeira \\
\hline Melo & $\mathrm{F}$ & 18.02 .1976 & $\begin{array}{l}\text { Santo Antônio } \\
\text { de Jesus }\end{array}$ & Enfermagem & $\begin{array}{l}\text { Santo Antônio } \\
\text { de Jesus }\end{array}$ \\
\hline Sales & $\mathrm{F}$ & 22.01 .1985 & Amargosa & Pedagogia & Amargosa \\
\hline Freitas & $M$ & 03.01 .1988 & $\begin{array}{l}\text { Conceição do } \\
\text { Almeida }\end{array}$ & História & Cachoeira \\
\hline Pereira & $M$ & 05.03 .1982 & $\begin{array}{l}\text { Cabaçeiras do } \\
\text { Paraguaçu }\end{array}$ & Agronomia & Cruz das Almas \\
\hline Oliveira & $\mathrm{F}$ & 11.03 .1978 & Amargosa & Psicologia & $\begin{array}{l}\text { Santo Antônio } \\
\text { de Jesus }\end{array}$ \\
\hline Souza & $\mathrm{F}$ & 12.11.1984 & Salvador & Museologia & Cachoeira \\
\hline P. da Silva & $\mathrm{F}$ & 27.10.1985 & Cruz das Almas & Museologia & Cachoeira \\
\hline Almeida & $\mathrm{F}$ & 02.02.1984 & Amargosa & Pedagogia & Amargosa \\
\hline dos Santos & $\mathrm{F}$ & 06.02 .1982 & $\begin{array}{l}\text { Conceição } \\
\text { da Feira }\end{array}$ & Museologia & Cachoeira \\
\hline Fonseca & $\mathrm{F}$ & 18.04 .1981 & Sapeaçu & Enfermagem & $\begin{array}{l}\text { Santo Antônio } \\
\text { de Jesus }\end{array}$ \\
\hline E.Santos & $M$ & 07.08 .1987 & Amargosa & Pedagogia & Amargosa \\
\hline S Silva & $\mathrm{F}$ & 16.02 .1980 & Alagoinhas & Matemática & Amargosa \\
\hline Santos & M & 19.03 .1980 & $\begin{array}{l}\text { Santo Antônio } \\
\text { de Jesus }\end{array}$ & Psicologia & $\begin{array}{l}\text { Santo Antônio } \\
\text { de Jesus }\end{array}$ \\
\hline J Santos & $\mathrm{F}$ & 03.05 .1985 & Salvador & Matemática & Amargosa \\
\hline Rocha & $\mathrm{F}$ & 15.08 .1982 & São Felipe & Agronomia & Cruz das Almas \\
\hline Borges & $\mathrm{F}$ & 06.06.1981 & Ubaíra & Pedagogia & Amargosa \\
\hline Silveira & $\mathrm{F}$ & 26.10 .1977 & Cruz das Almas & Nutrição & $\begin{array}{l}\text { Santo Antônio } \\
\text { de Jesus }\end{array}$ \\
\hline Mercês & $\mathrm{F}$ & 12.10 .1983 & Pintadas & Enfermagem & $\begin{array}{l}\text { Santo Antônio } \\
\text { de Jesus }\end{array}$ \\
\hline Gusmão & $\mathrm{F}$ & 02.03 .1979 & Salvador & Agronomia & Cruz das Almas \\
\hline Salvador & $\mathrm{F}$ & 03.05.1988 & Muritiba & Museologia & Cachoeira \\
\hline Ferreira & $M$ & 01.07 .1988 & Brejões & Física & Amargosa \\
\hline Silva & $\mathrm{F}$ & 13.06 .1986 & Salvador & Agronomia & Cruz das Almas \\
\hline Brito & $\mathrm{F}$ & 13.05 .1986 & Amargosa & Pedagogia & Amargosa \\
\hline Santos & $M$ & 18.12 .1985 & São Félix & Comunicação & Cachoeira \\
\hline Paixão & $\mathrm{F}$ & 13.07.1989 & Amargosa & Pedagogia & Amargosa \\
\hline
\end{tabular}

Fonte: Autor. 
As estratégias educacionais construídas no Conexões de Saberes da UFRB visavam ao combate ao racismo e à discriminação, reconhecendo as políticas de reparação voltadas para a educação dos negros, como também a conscientização de que os negros e os não negros precisam ter acesso a conhecimentos que fortaleçam as novas relações étnico-raciais e sociais que se estabelecem. Estratégia metodológica que ocorreu com o propósito de conjugar as ações de formação acadêmica, as políticas de permanência e de extensão.

Nas Rodas de Saberes e Formação, tecnologia pedagógica, criadas e realizadas pelos professores e estudantes que participaram do Conexões de Saberes da UFRB, todos os participantes tinham algo a ouvir e algo a dizer sobre suas dificuldades na formação básica, suas histórias de vida e seus conhecimentos ancestrais, assim as aprendizagens se construíram por meio da relação entre os sujeitos. Relação facilitada pela configuração em roda, onde as experiências foram partilhadas, ocorrendo a troca de olhares e a construção de novos argumentos.

Em algumas de suas obras, Paulo Freire refere-se à importância da pedagogia do diálogo para a educação, afirmando que "ninguém sabe tudo, ninguém é inteiramente ignorante" (FREIRE, 1989, p.17). O diálogo aproxima as pessoas e enriquece o saber, além de ser fundamental para a educação, é um processo permanente e não acontece somente no espaço acadêmico, pois o indivíduo vive em comunidade e o ato educativo se constitui a partir da vida do povo, desde o seu nascimento até a morte.

Momentos dialógicos marcaram o Programa na UFRB com alguns jovens que, durante o período do Conexões de Saberess participaram do processo de ensino e de aprendizagem com os coordenadores, tutores e os parceiros, os alunos dos municípios, nas escolas das comunidades, espaços escolares que os universitários já conheciam, por terem sido egressos do ensino médio.

De início, os alunos do ensino médio foram incentivados a participarem dos momentos de diálogo nas Rodas de Saberes e Formação. Após alguns encontros, os temas explorados tornaram-se interessantes por fazerem parte das suas vidas, crescendo não só a quantidade de alunos como a exposição de ideias.

Como princípio fundamental nas Rodas de Saberes e Formação, imperava a dialogicidade, método que os pedagogos, coordenadores do projeto, professores doutores em educação, asseguravam a todo momento, pois a ideia era a construção do conhecimento por meio do diálogo entre as comunidades e a universidade.

Sobre as Rodas de Saberes e Formação, os coordenadores do Conexões de Saberes da UFRB, Jesus e Nascimento (2012) descrevem:

A Roda de Formação é uma metodologia de ação, uma tecnologia pedagógica criada e realizada pelos coordenadores da PROPAAE, professores e estudantes da UFRB. Elas promovem o debate de temas transversais nos currículos das escolas, e proporciona a 
reflexão coletiva e horizontalizada sobre questões e temas previamente elencados, presentes nos movimentos sociais e políticos locais, a exemplo das ações afirmativas, implantação das leis 10.63903 e 11.645-08, questões de gênero e identidades, do protagonismo juvenil, políticas de acesso e permanência no ensino superior, enfocados a partir da sistemática de relatos, experiências e discussões (JESUS; NASCIMENTO, 2012, p.320).

Pensamento contemporâneo que comungava com o de Paulo Freire, quando da criação do Círculo de Cultura junto com o Método de Alfabetização, em Recife, na década de 1960. O Círculo de Cultura era um trabalho pedagógico realizado com os analfabetos adultos que tinha as seguintes características: diálogo, participação e respeito ao/a outro/a. Com a proposta de preparar o terreno, a equipe de coordenação e os educadores juntavam-se aos adultos analfabetos, participantes do Círculo e, de início, realizavam um levantamento temático, cujo objetivo era organizar a programação, levando-se em conta os aspectos didático-pedagógicos com a utilização de todos os recursos de ensino, a exemplo do projetor de slide e gravador, que, à época, era o que mais de avançado havia à disposição da educação.

Padilha (2003), na sua Tese de Doutorado em Educação, explica a denominação do termo Círculo de Cultura, usado por Paulo Freire. Com a visão de que o homem é um ser relacional, criador de cultura, Paulo Freire, sob o cenário da República Populista (1950 - 64) no Brasil, sobretudo no Recife, não deixou de ter influências, desenvolvendo suas principais concepções teóricas, ideias e categorias, explicitadas no livro Educação e Atualidade Brasileira (FREIRE, 2001). Para Freire, "a cultura é mais ampla, transcende e supera a compreensão do que seja a própria educação, mas com ela se relaciona permanente, sem nunca dela dissociar-se, a não ser por uma atuação político-pedagógica, diríamos mais, ideologicamente situada, que vise a separar e dicotomizar cultura e educação" (PADILHA, 2003, p.162).

A cultura tem uma relação com a sociedade. Com todas as teorias desenvolvidas sobre a cultura, através dos tempos, uma importante interpretação que podemos fazer é que a cultura está relacionada com a sociedade onde os homens/as mulheres pensam, comunicam e transmitem seus conhecimentos entre as próprias gerações e, também, para povos diferentes. Com a propagação dos seus valores e normas através da linguagem, seja oral ou escrita, os povos vão adquirindo novos saberes, constatando, assim, suas variações culturais entre os seres humanos, o que determina a existência de diferentes tipos de sociedade.

Os homens/mulheres que participavam dos Círculos de Cultura eram analfabetos/as, mas traziam a sua cultura e os seus saberes através da linguagem oral. Eram respeitados/as nas subjetividades através de suas falas, na construção da identidade e, nesse processo, levando-se em conta as manifestações, um currículo mais significativo era construído. Conforme Freire (2003), o objetivo "era alfabetizar em posição de tomada de consciência, na emersão que fizera no processo de nossa 
realidade. Num trabalho com que tentássemos a promoção da ingenuidade em criticidade, ao mesmo tempo em que alfabetizássemos". (FREIRE, 2003, p.113).

A alfabetização de Paulo Freire seja em Angicos - Brasil (1962) ou GuinéBissau-Africa (1970), lugares em que utilizou o método de trabalho, Circulo de Cultura, não era, simplesmente, uma alfabetização, para que os adultos assinassem o próprio nome ou garantissem o direito do voto, e sim, uma alfabetização política, cujo objetivo era provocar essas pessoas, para que pudessem sair da cultura do silêncio.

Passaram-se mais de cinquenta anos e as experiências de Paulo Freire com os analfabetos adultos nos Círculos de Cultura ainda são referenciais. E, hoje, os encontros didático-pedagógicos, realizados entre pessoas ou grupo de pessoas, seja na academia, nos espaços culturais, nas organizações não governamentais etc., nos remetem ao trabalho didático-pedagógico realizado pelo criador dos Círculos de Cultura.

Numa proposta metodológica diferente e com outras nomenclaturas, o constructo teórico de Paulo Freire é referência, permanecendo elementos que contribuem para a constante articulação entre a pesquisa, o ensino, a transdisciplinaridade, a cultura, entre outros.

No livro Educação como Prática da Liberdade, o autor explica os Círculos de Cultura:

\begin{abstract}
Em lugar de escola, que nos parece um conceito, entre nós, demasiado carregado de passividade, em face de nossa própria formação (mesmo quando se lhe dá o atributo de ativa), contradizendo a dinâmica fase de transição, lançamos o Circulo de Cultura. Em lugar de professor, com tradições fortemente doadoras, o Coordenador de Debates. Em lugar de aula discursiva, o diálogo. Em lugar de aluno, com tradições passivas, o participante de grupo. Em lugar dos pontos e de programas alienados, programação compacta, reduzida e codificada em unidades de aprendizado (FREIRE, 2003, p.111).
\end{abstract}

Diante disso, percebemos que há pontos em comum entre os Círculos de Cultura de Paulo Freire e as Rodas de Saberes e Formação, proposta metodológica do Programa Conexões de Saberes da UFRB.

E, nessa metodologia do Conexões de Saberes, na figura geométrica do círculo, todos os participantes dialogam, olham-se e veem-se, promovendo a horizontalidade na relação, a valorização da cultura e da oralidade.

A problematização e a aprendizagem estão sempre presentes, mas é por intermédio dos diferentes olhares sobre a realidade que os participantes constroem suas identidades individuais e coletivas, respeitam a cultura do outro e, numa reflexão permanente, aprendem e reconstroem os seus conhecimentos.

Na nossa reflexão, a metodologia de trabalho nos Círculos de Cultura difere das 
Rodas de Saberes e Formação, considerando que, nos anos 60, a proposta era a construção de um currículo com base na cultura dos participantes que eram analfabetos. Mas, há uma contribuição dos elementos dessa metodologia às Rodas, no que se refere à participação, aos momentos de diálogos, à construção do conhecimento e ao respeito das comunidades rurais em relação à academia. São elementos herdados, mas que a cada tempo são trabalhados de diversas formas a depender do contexto em que se vive.

Como exercício inicial nas Rodas de Saberes e Formação e para fortalecer a autoestima e os vínculos com as comunidades de origem, a memória dos universitários foi resgatada, e, considerando que era imprescindível o autoconhecimento, a identificação de sua gênese como descendentes de africanos e o re-conhecimento da própria comunidade que, a exemplo da localidade de Três Lagoas, situada na zona rural de Amargosa, tinha à época, e ainda tem, um laço muito estreito com a natureza por ser remanescente de quilombos.

\section{EDUCAÇÃO AFRODESCENDENTE NAS RODAS DE SABERES E FORMAÇÃO}

A luta por uma educação de qualidade sempre ocorreu no cenário político brasileiro, por meio dos movimentos sociais populares, principalmente, porque a maioria das pessoas afrodescendentes não tinha o privilégio da educação. Como fruto da luta, principalmente do movimento negro, os afrodescendentes foram privilegiados na educação, através da Lei 10.639, de 09 de janeiro de 2003, que decretou a obrigatoriedade do Ensino de História e Cultura Afro-Brasileira. Após cinco anos, houve uma alteração através da Lei 11.645 , de 10 de março de 2008, que incluiu, também, nos conteúdos o ensino de história e cultura dos povos indígenas brasileiros.

As razões do atraso intelectual e formativo da educação se iniciaram desde os tempos da colônia, em que os filhos da aristocracia estudavam na Universidade de Coimbra, bastando um pouco da educação básica, clássica, ornamental ou livresca para os burocratas e filhos de homens livres dos centros urbanos. Esse dualismo da educação, no país, atravessou o período colonial, o império, até a nossa independência formal. $\mathrm{O}$ dualismo continuou com a primeira república, mantendo as prendas domésticas e ofícios de nível médio teoricamente para os pobres e a educação superior, clássica, ornamental, bacharelesca e profissionalizante, para a elite brasileira de cor branca, oferecida por Faculdades, até as primeiras décadas do Século XX. (LEITE, 1938-1948, t.VII, p.200-8 apud CUNHA, 2007a, p. 34).

A visão negativa sobre a etnia negra vem desde o Brasil Colônia e se propagou por séculos, influenciando nas vidas dessas pessoas, na construção da sua autoestima e da sua identidade.

Mesmo com os esforços na luta pela libertação, os africanos escravizados no Brasil trabalharam sob o domínio do homem branco nas lavouras e plantações, 
mostrando o sentimento de coragem e indignação diante da escravidão. É salutar registrar que os negros nunca aceitaram essa condição de escravos com passividade. As formas de resistência negra contra a escravidão tiveram como estratégias as revoltas, as fugas, assassinatos de senhores e suas famílias, abortos, quilombos, organização religiosa, entre outras.

A desigualdade racial que caminha ao lado da desigualdade de renda foi construída ao longo do processo histórico, político e social do Brasil que, diferentemente, afeta a população branca e negra, mas de modo particular, os negros nas condições de vida, emprego e escolaridade.

\begin{abstract}
Segundo dados da Pesquisa Nacional por Amostra de Domicílio, também realizada pelo IBGE em 1999, os negros e pardos representam $63 \%$ dos pobres e $68 \%$ dos indigentes, o que significa, em números absolutos, que existem no Brasil 33,7 milhões de brasileiros negros e pardos vivendo em condição de pobreza e 15,1 milhões vivendo em condições de indigência absoluta. Os negros e pardos também representam $70 \%$ dos $10 \%$ da população mais pobre do país, enquanto $85 \%$ dos $10 \%$ da população mais rica é branca (HENRIQUES, 2001, p. 1 - 46).

Em pesquisa mais recente realizada pela Organização Internacional do Trabalho (OIT), constatou-se que no Brasil um negro recebe, em média, metade do salário de um branco. A discriminação fica ainda mais evidente quando os dados dessa pesquisa revelam que entre 1992 e 2001 aumentou em aproximadamente $50 \%$ a quantidade de negros acima de 16 anos que possuíam mais de sete anos de estudo, saindo de um percentual de 23\% (em 1992) para 35\% (em 2001). Essa pesquisa ainda mostrou que o desemprego também prejudicou mais os negros, que as mulheres negras são as que estão mais excluídas do mercado de trabalho e que as mulheres, de maneira geral, recebem quase $80 \%$ do salário que um homem branco recebe, em média. (BRANDÃO, 2005, p.33-34)
\end{abstract}

A discriminação era notória em relação aos negros durante e após a escravidão, na primeira metade do Século XX, considerando que não possuíam uma educação de qualidade, exigida pelos padrões da elite brasileira. Não lhes era dada a oportunidade para o aprendizado e, consequentemente, era difícil superar as dificuldades em relação ao mercado de trabalho e outras possibilidades.

A discriminação se traduz na outorga, explícita ou dissimulada, de preferência no acesso à educação de qualidade a um grupo social em detrimento de outro[...] Prejudicados em um aspecto de fundamental importância para o ulterior desenrolar de suas vidas, os membros do grupo vitimado se vêem, assim desprovidos dos "meios" indispensáveis à sua inserção, em pé de igualdade com os benefícios da injustiça perpetrada, na competição pela obtenção de empregos e posições escassos no mercado de trabalho (GOMES, 2001 apud MEDEIROS, 2004,p.135)

No período em que a educação afrodescendente começou a ficar em evidência, o Programa Conexões de Saberes da UFRB, em suas Rodas de Saberes e Formação, trazia à tona os saberes populares da região do Recôncavo da Bahia, representados pelos estudantes, suas famílias e grupos de origem, aprendendo com os mais velhos 
ou aqueles que detêm a memória da região, como as lalorixás dos terreiros de Candomblé, como os Mestres da Capoeira, como as pioneiras do Samba-de-Roda, nas Casas de Farinha, na Agricultura de subsistência e no Artesanato étnico.

O Projeto Griôts $^{1}$ foi apresentado aos universitários afrodescendentes do Programa como referência para trabalhar a questão da ancestralidade.

Mas, as tradições eram respeitadas no interior das religiões de matriz africana e, num esforço conjunto, a memória continuava viva e não tinha "árvore do esquecimento", batismo cristão ou demonização das práticas africanas que fossem capazes de apagar a memória dos/as homens/mulheres africanos/as. E, como forma de resistência ao Novo Mundo, ainda incorporaram outros referenciais nos seus universos simbólicos.

Como a fortaleza dos africanos está na manutenção da religiosidade, a noção de ancestralidade é fundamental e, na contemporaneidade, nas religiões de matriz africana, percebemos a intimidade e o respeito pela natureza. O Recôncavo Baiano, desde o século XVIII, está carregado de uma religiosidade cuja procedência é de origem africana e não há como ficar alheio às ideias africanas nos locais onde se situa a UFRB.

Foi tomado como exemplo, ou melhor, como referência, a educação de base africana em que, embaixo da frondosa árvore do Baobá, no continente africano, homens e mulheres se reuniam para momentos de aprendizagem. Faziam parte desses encontros, além das pessoas, o silêncio e a própria natureza que, continuamente, tinha uma relação íntima com a comunidade.

Mesmo sem o Baobá, cenário inspirador das comunidades africanas, as Rodas de Saberes e Formação aconteciam em diversos cenários do Recôncavo, o que corroborava a orientação de estudiosos, a exemplo de Paulo Freire, de que a escola valorize a subjetividade com possibilidades de construção de um currículo investigativo, proporcionando ações reflexivas permanentes.

Nesse sentido, as Rodas de Saberes e Formação foram momentos únicos em que os estudantes aprenderam uma outra forma de promover práticas pedagógicas, que podiam ser também inseridas nas salas de aula da academia, o que quebraria a pedagogia tradicional, na qual o professor é o centro das atenções. Eles também puderam transpor os conhecimentos para além da universidade.

A Roda de Formação é uma metodologia de ação, uma tecnologia pedagógica criada e realizada pelos coordenadores da PROPAAE, professores e estudantes da UFRB. Elas promovem o debate de temas transversais nos currículos das escolas, e proporciona a reflexão coletiva e horizontalizada sobre questões e temas

\footnotetext{
${ }^{1}$ Griôts do Recôncavo subprojeto do Conexões de saberes, que surgiu em 2007 com a proposta de auxiliar na formulação de textos e concepção do Livro pedagógico utilizado pelos bolsistas nas rodas de formação e na pesquisa de campo: Textos temáticos para rodas de formação, atividades, lei 10.639/03 e parecer sobre a mesma, protagonismo juvenil, textos autobiográficos, poesias, imagens, calendário afirmativo, concepção de pesquisa tendo exu como inspiração metodológica.
} 
previamente elencados, presentes nos movimentos sociais e políticos locais, a exemplo das ações afirmativas, implantação das leis 10.63903 e 11.645-08, questões de gênero e identidades, do protagonismo juvenil, políticas de acesso e permanência no ensino superior, enfocados a partir da sistemática de relatos, experiências e discussões (JESUS; NASCIMENTO, 2012, p.320).

Esses momentos de construção de conhecimento em formato circular, conforme Soares (2012) lembram o modelo do candomblé:

Chamamos de xirê e é a grande saída para a criação do mesmo, uma
vez que a formação circular acaba com a hierarquia que possibilita o
nascimento da religião, formada por vários Orixás de nações
diversas, dando um exemplo de tolerância e diplomacia, gerida por
Exu, que convoca a todos para o culto em um ritual anterior ao xirê,
que é o padê, sendo que é o que o próprio Exu significa
conceitualmente, aquilo que é redondo, e por isso circular, assim
como o xirê, é o redondo e circular Exu que convida a todos para
dançar em círculo (SOARES, 2012, p.52).

\section{CONCLUSÃO}

Nas rodas de formação do Conexões de Saberes, todos são convidados a falar, sem destaque de autoridade do educador perante os educandos, esse modelo, cujo formato faz parte da filosofia da educação afrodescendente que tem como exemplo o xirê, roda da festa pública do candomblé, onde os orixás dançam em círculo, sem hierarquia entre eles e foi o modelo amplamente empregado pelo Conexões de Saberes, nos campi da UFRB, nas escolas de ensino médio e em outros espaços sociais.

Os educandos vinculados ao Programa Conexões de Saberes aprenderam a valorizar os saberes científicos, mas também a reconhecer os saberes tradicionais e populares como componentes importantes do saber social, inclusive como base para a formação intelectual. O conhecimento desenvolvido através das Rodas de Saberes e Formação, nos seminários e em outros eventos foram muito significativos e influenciaram no desenvolvimento social, psicológico e acadêmico dos estudantes. Enquanto profissionais não perderam a oportunidade de aplicar os conhecimentos no mercado de trabalho, de modo a promover maior integração social, colaboração, acolhimento e proatividade, como podemos ver nos depoimentos a seguir:

Utilizamos muito as metodologias das Rodas de Formações nos seminários em que fazíamos quando graduandos para quebrar um pouco o modo como eram feitos os seminários na nossa turma e esse conhecimento crítico do Conexões de Saberes eu usei muito no curso de jornalismo, muito na interpretação, principalmente, nas disciplinas de comunicação e política, nas disciplinas que envolviam a questão social. Eu transpus muito esse conhecimento para o curso, para interpretação das questões, para os seminários, para os temas que a gente trabalhava, pra tudo ( SANTOS, entrevistado em 24.04.2013).

Cheguei até a escrever um projeto sobre as rodas de formação e enviei para o Mestrado de Gestão de Políticas Públicas da UFRB, em Cruz das Almas, discutindo a importância das rodas de formação como uma tecnologia didática diferenciada, porque na roda de 
formação você não tem aquele que ensina, simplesmente, você tem aquele que fomenta, mas todos participam da roda. [...] Como Prof. Cláudio Orlando fala, a roda vem de uma ancestralidade da herança oral principalmente das culturas africanas e indígenas. Então, esse momento de roda é um momento de aprendizagem. E o interessante da roda é o respeito que não tem hierarquia, todo mundo fala, todo mundo ouve e todo mundo se olha e todo mundo se enxerga dentro da roda. É uma fruição de conhecimento muito gostosa de se vivenciar e eu como professora eu aplico muito essa ... (riso) eu comecei a aplicar muito isso porque quando você colega crianças em roda algumas são mais tímidas, mas quando elas veem os outros falando falam também e é uma coisa interessante a vivência na roda. Por que a roda realmente ela estimula o desapego falar, o se colocar ali, todos estão ali então você pode estar ali... falando. É muito interessante (PAIXÃO, entrevistada em 25.04.2013).

Eu me formei sendo conexista...Finalizando o meu período do Conexões de Saberes e já finalizando o meu período de Faculdade. O Conexões de Saberes eu posso dizer, inclusive, que... eu sempre busquei a minha permanência da universidade e o CS ele me promoveu a minha permanência mais qualificada na universidade. Porque eu estava dentro da universidade e o CS não influenciava nos meus horários de estudos. Se eu tinha que estudar, fazer uma prova, um seminário eu não tinha que largar as minhas atividades pra fazer as atividades do CS, não. A coordenação também era muito flexível com a gente. Então eu pude ter realmente ter uma permanência qualificada enquanto eu estava no Conexões. Ai eu tive mais tranquilidade para formar. Tive uma dificuldade no final, fiquei com poucas matérias, formei com duas matérias apenas (as engenharias hidráulica e irrigação). Por que no período eu precisei fazer uma cirurgia também e aí tive um problema... o professor não aceitou fazer segunda chamada, perdi... fiquei com duas matérias e pude me dedicar mais ao CS. [...] Então, quando encerrei a faculdade eu também já recebi algumas propostas de emprego (GUSMÃO, entrevistada em 08.05.2013).

Depois do Conexões de Saberes, ainda graduanda, tive a oportunidade de trabalhar como secretária do Curso de Especialização em História da África, realizado pelo NEAB/UFRB, em Amargosa, sob a coordenação do Professor Emanoel Soares. Outras oportunidades surgiram na universidade, mas não tive como aproveitar, devido aos horários e o transporte. Afinal, não há disponibilidade de transporte para o local onde moro. [...] Atualmente, dedico-me aos afazeres da casa, ao meu pequeno e com um pouco de dificuldade à escrita da monografia (E. SANTOS, entrevistada em 19.05.2013).

Os jovens partícipes do Programa Conexões de Saberes reconhecem que foi importante se conhecer, aprender a atuar e opinar nos eventos educativos, dentro e fora da UFRB. Hoje, são estudantes com identidades sociais, culturais e econômicas definidas, problematizadas e contextualizadas, e isso Ihes serve como pilares para sua atuação como profissionais com autonomia e responsabilidade.

A integração entre os jovens universitários e as comunidades escolares foi um dos pontos importantes do Programa proporcionando, de forma significativa, um retorno positivo para os jovens das escolas públicas de ensino médio da região, estreitando os laços entre essas comunidades escolares, a partir das vivências dos jovens acadêmicos. 


\section{REFERÊNCIAS}

BRANDÃO, C. F. As cotas na universidade pública brasileira: será esse o caminho? Campinas, SP: Autores Associados, 2005.

CUNHA, L. A. A universidade temporã: o ensino superior, da Colônia à Era Vargas. 3. ed. São Paulo: Editora UNESP, 2007.

FREIRE, P. A importância do ato de ler: em três artigos que se completam. 23. ed. São Paulo: Autores Associados: Cortez, 1989.

FREIRE. P. Educação e atualidade brasileira. São Paulo: Cortez/IPF, 2001.

FREIRE, P. Educação como Pratica da Liberdade. 27. ed. Rio de Janeiro: Paz e Terra, 2003.

HENRIQUES, R. Desigualdade Racial no Brasil: Evolução das Condições de Vida na Década de 90. Texto para Discussão 807. Rio de Janeiro: Instituto de Pesquisa Econômica Aplicada. 2001.

JESUS, R. C. D. P.; NASCIMENTO, C. O. C (Orgs). Para fazer conexões: universidade, ações afirmativas, diversidade. Cruz das Almas, Salvador: UFRB, 2012.

MEDEIROS. C. A. Na lei e na raça: Legislação e relações raciais, Brasil-Estados Unidos. Rio de Janeiro: DP\&A, 2004.

MIDIARECONCAVO, 2013. Disponível em:

<http://www.midiareconcavo.com.br/admin/noticias/16-03-2013_08_29_39.gif >.

Acesso em: 10 fev. 2015.

PADILHA, P. R. Currículo intertranscultural: por uma escola curiosa, prazerosa e aprendente. 2003. Tese (Doutorado em Educação) - Faculdade de Educação, Universidade de São Paulo, 2003.

SOARES. E. L. R. Memórias da gestão da PROPAAE/Campus de Amargosa. In: JESUS, R.C.D.P.; NASCIMENTO, C.O.C. Para fazer conexões: universidade ações afirmativas diversidade. Cruz das Almas, Salvador: UFRB, 2012. 